\title{
Environmental Conditioning and Aerosol Infection of Mice
}

\author{
Eriko Kudo1, * and Akiko Iwasaki ${ }^{1,2}$
}

\author{
1Department of Immunobiology, Yale University School of Medicine, New Haven, CT 06520, USA; \\ ${ }^{2}$ Howard Hughes Medical Institute, Chevy Chase, Maryland, USA \\ *For correspondence: eriko.kudo@yale.edu
}

\begin{abstract}
[Abstract] Influenza infection models in mice are widely used to study flu-mediated immune responses and pathology. However, most laboratory mice are housed at $20^{\circ} \mathrm{C}$ and $50 \%$ relative humidity (RH). To better recapitulate influenza epidemics and immune responses during winter seasons, mice were housed at $20{ }^{\circ} \mathrm{C}$ under different humidity conditions, $10-20 \%$ or $50 \% \mathrm{RH}$. Here, we describe a protocol for using aerosolized droplets to infect mice with influenza under different environmental conditions. Using this method enables influenza infection studies performed under more physiologically relevant conditions which better mimics human viral exposure.
\end{abstract}

Keywords: Influenza, Humidity, Environment, Mouse, Infection, Aerosol challenge

[Background] Influenza A viruses (IAVs) are one of the major causes of seasonal respiratory infections in the world, resulting in half million deaths annually (Johnson et al., 2014). IAV outbreaks occur during the winter season in temperate regions, peaking between November and March in the Northern Hemisphere and between May and September in the Southern Hemisphere (Tamerius et al., 2013; Alonso et al., 2015). Virological research in guinea pigs shows that low temperature and humidity enables better aerosol transmission of influenza virus (Lowen et al., 2007). In addition, epidemiological studies demonstrate that a drop in absolute humidity correlates closely with the rise in influenza-related deaths in humans (Shaman et al., 2010). It is worth noting that in tropical and subtropical climate regions, which are wet and warm, the virus can thrive on surfaces of objects and cause fomite transmission (Shek and Lee, 2003, Moura et al., 2009).

Laboratory mice are generally maintained at macroenvironmental temperature and relative humidity ranges of 64 to $79{ }^{\circ} \mathrm{F}\left(17.8\right.$ to $26.1{ }^{\circ} \mathrm{C}$ ) and $30 \%$ to $70 \%$, respectively (Clark et al., 1997). However, these environmental conditions do not reflect our home, office or school in the winter season. Moreover, intranasal inoculation of virus using pipette is the most standard route used to study influenza infection in mice, which significantly affects the effective humidity in the upper respiratory system, as a liquid solution is being delivered. On the contrary, influenza infections between humans occur by either aerosol droplets or through contaminated surface contact (Lakdawala and Subbarao, 2012). Therefore, to better mimic human infection, we utilized a protocol to infect mice with influenza virus through aerosol exposure after housing the animals in dry air conditions, similar to house found in the winter months. In this protocol, we describe the use of an environmental chamber to mimic indoor conditions found during the winter seasons, namely, $20^{\circ} \mathrm{C}$ and $10-20 \% \mathrm{RH}$, along with the use of a nebulization system. 


\section{Materials and Reagents}

1. $15 \mathrm{ml}$ conical tube (BD Falcon, catalog number: 352096)

2. Pipette tips (Fisherbrand, catalog numbers: 02-681-165, 02-681-147 or equivalent)

3. C57BL/6 mice carrying a functional $M x 1$ allele (Horisberger et al., 1983) Note: Most laboratory mouse strains are highly susceptible to influenza infection due to a defective Mx1 gene which is an important interferon stimulated gene to combat influenza (Iwasaki, 2016). Therefore, we prefer to use Mx1 congenic B6 mice to study host responses to influenza viruses.

4. Highly virulent A/PR/8/34 (H1N1; hvPR8) (Grimm et al., 2007)

Previously, the hvPR8 strain was generated by serial lung passages in Mx1 mice (Grimm et al., 2007).

5. 1x PBS (Sigma, catalog number: D8537)

\section{Equipment}

1. Environmental chamber (Caron, model: 7000-10)

2. Nebulizer (Allied Healthcare Products, Schuco, model: S5000)

3. Mouse pie cage (Braintree Scientific, model: MPC-3 AERO)

4. Weight scaler (OHAUS, Scout Pro, model: SP202)

5. Pipettes (DENVILLE, P1000, P200)

\section{Software}

1. GraphPad Prism 7.0 (GraphPad Software; https://www.graphpad.com/)

\section{Procedure}

A. Pre-conditioning of mice in environmental chambers

1. Transfer the mice to biosafety level 2 (BSL2) adaptive feeding for 3-7 days. Divide the mice randomly for housing under different humidity conditions at $20^{\circ} \mathrm{C}, 5$ mice for each group.

2. House the mice in cages placed in chambers set to either $20 \%$ or $50 \% \mathrm{RH}$ for $5-7$ days.

B. Influenza infection via aerosol exposure (to be carried out under BSL2 condition)

1. Dilute hvPR8 $2 \times 10^{5} \mathrm{pfu} / \mathrm{ml}$ in PBS and prepare $4 \mathrm{ml}$ of diluted virus solution.

Note: This virus concentration is the lethal dose $50\left(L D_{50}\right)$ for this study. If you change influenza virus or mouse strain, you should determine $L D_{50}$ for your conditions before the experiment following this protocol. General protocol of measurement of $L D_{50}$ is reported in Zhao et al. (2018).

2. Put mice (up to 12 mice simultaneously) in the pie cage. 
3. Set nebulizer and pour $4 \mathrm{ml}$ of diluted virus solution ( $3 \mathrm{ml}$ is exact volume that would be will be used during $15 \mathrm{~min}$ of aerosol delivery).

4. Turn on the switch for the nebulizer and expose for $15 \mathrm{~min}$ (Figure 1 and Video 1).

A

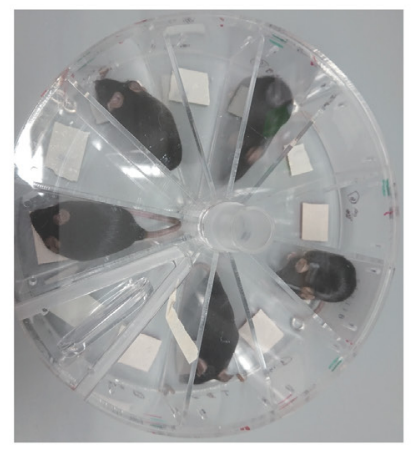

B

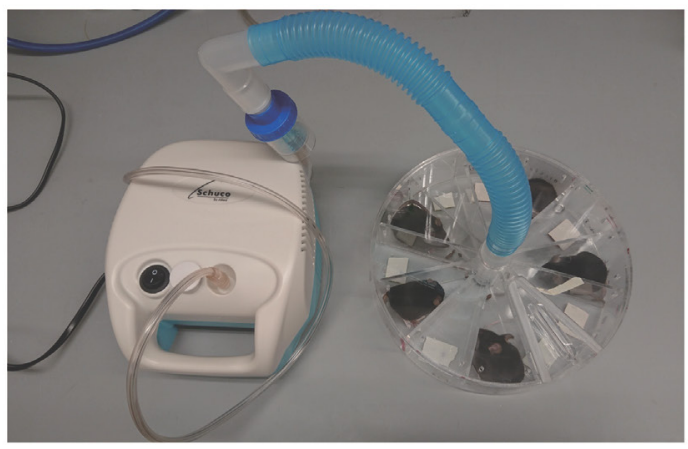

Figure 1. Representation of how to infect influenza virus in mice using a nebulizer. A. Mice are diagonally put into the pie cage if the number of mice is less than 12. B. Image of connected pie cage and nebulizer.

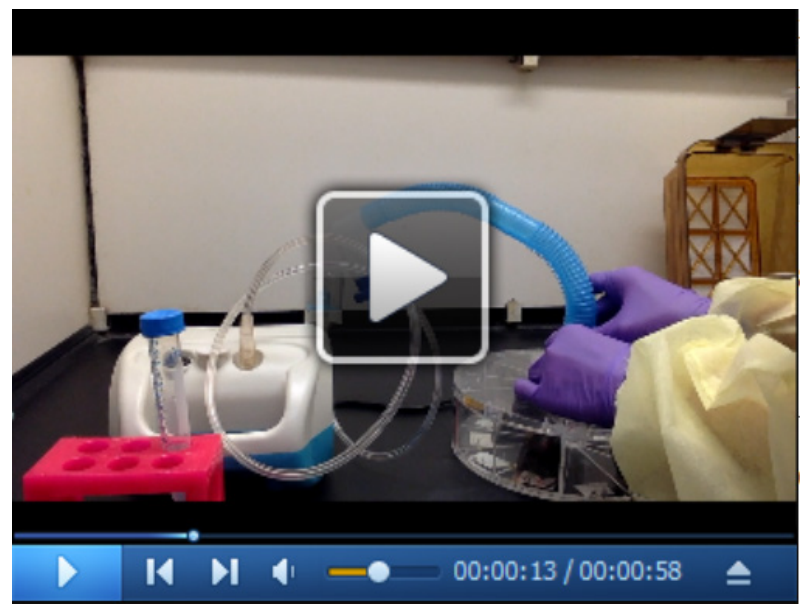

Video 1. Infection via aerosol administration

5. Put mice back in the cage and house them at respective environmental conditions.

6. Monitor the weight and death of the mice for 2 weeks (Figure 2 and Video 2). Euthanize the animals according to the guidelines of the institutional animal care and use committee. 


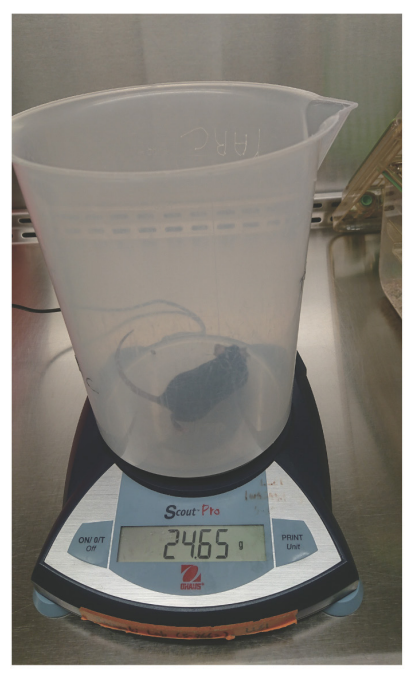

Figure 2. Measuring of body weight Mouse put on the weight scaler to measure the body weight

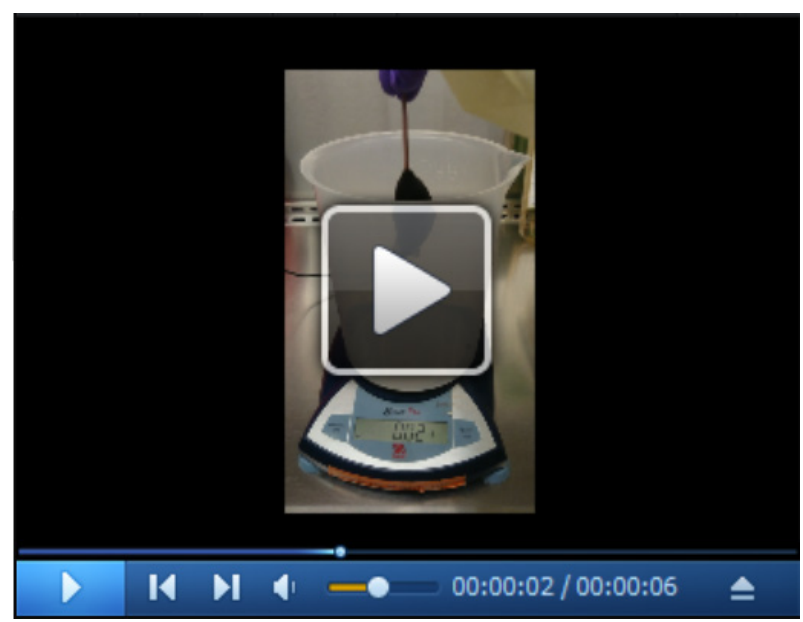

\section{Video 2. Measure the body weight}

\section{Data analysis}

Survival curve and weight loss are analyzed using GraphPad Prism (Figure 3).

A

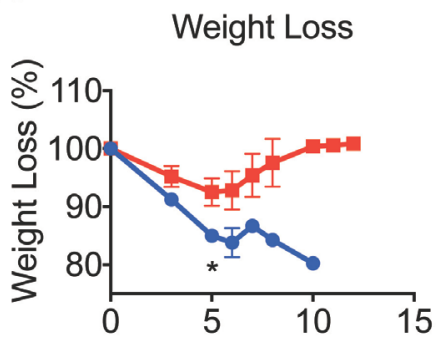

Days after Virus Challenge
B

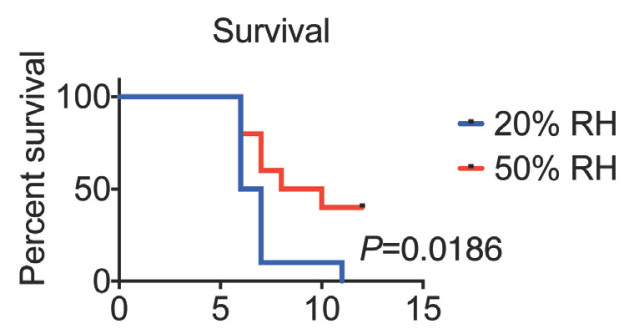

Days after Virus Challenge

Figure 3. Low relative humidity leads to more severe disease. (A) Weight and (B) survival were 
monitored for 11 days. Data are representative of five experiments and means \pm SEM ${ }^{*} P<0.05$; one-way ANOVA; log-rank (Mantel-Cox) (Adapted from Kudo et al., 2019).

\section{Acknowledgments}

This work was supported in part by the Howard Hughes Medical Institute (A.I.), a gift from the Condair Group, the Naito Foundation (E.K.). An abbreviated version of this protocol was originally published in "Low ambient humidity impairs barrier function and innate resistance against influenza infection" (Kudo et al., 2019).

\section{Competing interests}

The authors declare no competing interests.

\section{Ethics}

All procedures used in this study complied with federal and institutional policies of the Yale Animal Care and Use Committee (protocol \#10365).

\section{References}

1. Alonso, W. J., Yu, C., Viboud, C., Richard, S. A., Schuck-Paim, C., Simonsen, L., Mello, W. A. and Miller, M. A. (2015). A global map of hemispheric influenza vaccine recommendations based on local patterns of viral circulation. Sci Rep 5: 17214.

2. Clark, J. D., Gebhart, G. F., Gonder, J. C., Keeling, M. E. and Kohn, D. F. (1997). The 1996 guide for the care and use of laboratory animals. ILAR Journal 38(1): 41-48.

3. Grimm, D., Staeheli, P., Hufbauer, M., Koerner, I., Martinez-Sobrido, L., Solorzano, A., GarciaSastre, A., Haller, O. and Kochs, G. (2007). Replication fitness determines high virulence of influenza a virus in mice carrying functional Mx1 resistance gene. Proc Natl Acad Sci U S A 104(16): 6806-6811.

4. Horisberger, M. A., Staeheli, P. and Haller, O. (1983). Interferon induces a unique protein in mouse cells bearing a gene for resistance to influenza virus. Proc Natl Acad Sci U S A 80(7): 1910-1914.

5. Iwasaki, A. (2016). Antiviral responses of inbred mice. Nat Rev Immunol 16(6): 339.

6. Johnson, N. B., Hayes, L. D., Brown, K., Hoo, E. C., Ethier, K. A., Centers for Disease, C. and Prevention (2014). CDC National Health Report: leading causes of morbidity and mortality and associated behavioral risk and protective factors--United States, 2005-2013. MMWR Suppl 63(4): 3-27. 
7. Kudo, E., Song, E., Yockey, L. J., Rakib, T., Wong, P. W., Homer, R. J. and Iwasaki, A. (2019). Low ambient humidity impairs barrier function and innate resistance against influenza infection. Proc Natl Acad Sci U S A 116(22): 10905-10910.

8. Lakdawala, S. S. and Subbarao, K. (2012). The ongoing battle against influenza: The challenge of flu transmission. Nat Med 18(10): 1468-1470.

9. Lowen, A. C., Mubareka, S., Steel, J. and Palese, P. (2007). Influenza virus transmission is dependent on relative humidity and temperature. Plos Pathogens 3(10): 1470-1476.

10. Moura, F. E., Perdigao, A. C. and Siqueira, M. M. (2009). Seasonality of influenza in the tropics: a distinct pattern in northeastern Brazil. Am J Trop Med Hyg 81(1): 180-183.

11. Shaman, J., Pitzer, V. E., Viboud, C., Grenfell, B. T. and Lipsitch, M. (2010). Absolute humidity and the seasonal onset of influenza in the continental United States. PLoS Biol 8(2): e1000316.

12. Shek, L. P. and Lee, B. W. (2003). Epidemiology and seasonality of respiratory tract virus infections in the tropics. Paediatr Respir Rev 4(2): 105-111.

13. Tamerius, J. D., Shaman, J., Alonso, W. J., Bloom-Feshbach, K., Uejio, C. K., Comrie, A. and Viboud, C. (2013). Environmental predictors of seasonal influenza epidemics across temperate and tropical climates. PLoS Pathog 9(3): e1003194.

14. Zhao, B. Shan, J., Xiong, R., Xu, K. and Li, B. (2018). H1N1 Virus Production and Infection. Bioprotocol 8(20): e3062. 